\title{
Operability assessment in CTEPH: Lessons from the CHEST-1 study
}

\author{
David P. Jenkins, BSc, MBBS, FRCS (CTh), MS, ${ }^{a}$ Andrzej Biederman, MD, ${ }^{\mathrm{b}}$ Andrea M. D’Armini, MD, \\ Philippe G. Dartevelle, MD, ${ }^{\mathrm{d}}$ Hui-Li Gan, MD, ${ }^{\mathrm{e}}$ Walter Klepetko, MD, \\ Jaroslav Lindner, MD, ${ }^{\mathrm{g}}$ Eckhard Mayer, MD, ${ }^{\mathrm{h}}$ and Michael M. Madani, MD ${ }^{\mathrm{i}}$
}

\begin{abstract}
Pulmonary endarterectomy is the gold standard treatment for chronic thromboembolic pulmonary hypertension and is potentially curative, although some patients are unsuitable for pulmonary endarterectomy and require alternative management. Lack of standardized assessment of pulmonary endarterectomy eligibility risks suboptimal treatment in some patients. We discuss the implications for future clinical trials and practice of a unique operability assessment in patients who have chronic thromboembolic pulmonary hypertension and were initially screened for inclusion in the CHEST-1 (Chronic Thromboembolic Pulmonary Hypertension Soluble Guanylate Cyclase Stimulator Trial-1) study. The CHEST-1 study evaluated riociguat for the treatment of inoperable chronic thromboembolic pulmonary hypertension (CTEPH) or persistent/recurrent pulmonary hypertension after pulmonary endarterectomy. Screened patients who were initially considered "inoperable" underwent central independent adjudication by a committee of experienced surgeons, or local adjudication in collaboration with an experienced surgeon. Operability decisions were based on accessibility of thrombi and the association between pulmonary vascular resistance (PVR) and the extent of obstruction, using pulmonary angiography/computed tomography with ventilation/perfusion scintigraphy as the minimum diagnostic tests. Of 446 patients screened for CHEST-1, a total of 188 and 124 underwent central and local adjudication, respectively, after being initially considered to be "inoperable." After a second assessment by an experienced surgeon, 69 of these 312 "inoperable" patients were deemed operable. Rigorous measures in CHEST-1 guaranteed that only technically inoperable patients, or patients who had persistent/recurrent pulmonary hypertension, were enrolled, thus ensuring that only patients for whom surgery was not an option were enrolled. This study design sets new standards for future clinical trials and practice in CTEPH, helping to ensure that patients who have CTEPH receive optimal treatment. (J Thorac Cardiovasc Surg 2016;152:669-74)
\end{abstract}

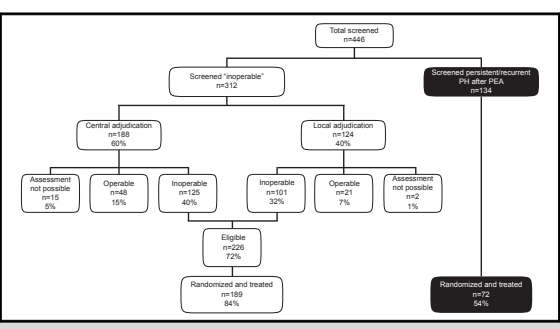

Classification of surgical eligibility after operability assessment in the CHEST-1 study.

\section{Central Message}

The CHEST-1 operability assessment sets new standards for CTEPH trials, ensuring that patients who are eligible for pulmonary endarterectomy are correctly identified.

\section{Perspective}

Pulmonary endarterectomy is potentially curative in CTEPH. Some patients are ineligible for the surgery, but operability assessment is complex and subjective, and patients can be wrongly designated as inoperable. The operability assessment methodology presented here from the CHEST-1 study is designed to ensure that all patients who may benefit from pulmonary endarterectomy are correctly identified.

See Articles page 763 and 872

See Editorial Commentaries page 675 771 , and 879 .

See Editorial page 656.

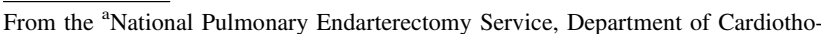
racic Surgery, Papworth Hospital, Cambridge, United Kingdom; ${ }^{b}$ Department of Cardiac Surgery, Allenort Hospital, Warsaw, Poland; ' ${ }^{\mathrm{C}}$ Division of Cardiothoracic Surgery, Foundation "I.R.C.C.S. Policlinico San Matteo," University of Pavia School of Medicine, Pavia, Italy; ${ }^{\mathrm{d} D e p a r t m e n t}$ of Thoracic and Vascular Surgery and Heart Lung Transplantation, Marie-Lannelongue Hospital, Paris-Sud University, Le Plessis-Robinson, France; ${ }^{\mathrm{e}}$ Department of Cardiac Surgery, Beijing Anzhen Hospital, Capital Medical University, Beijing Institute of Heart, Lung, and Blood Vessel Disease, Beijing, China; ${ }^{\mathrm{f}}$ Department of Cardiothoracic Surgery, Vienna General Hospital, Medical University of Vienna, Vienna, Austria; ${ }^{\mathrm{g}}$ 2nd Surgical Department-Clinical Department of Cardiovascular Surgery, First Faculty of Medicine and General Teaching Hospital, Charles University Prague, Prague, Czech Republic; ' Kerckhoff Heart and Lung Center, Bad Nauheim, Germany; and ${ }^{\mathrm{i}}$ Division of Cardiovascular and Thoracic Surgery, University of California San Diego Medical Center, San Diego, Calif.

D.P.J., A.B., W.K., J.L., P.G.D., H.-L.G., and M.M.M. were members of the CHEST-1 operability assessment committee and contributed to the analysis and interpretation
}

of data. A.M.D. was a CHEST-1 investigator directly involved in the recruitment and care of the participants, a member of the CHEST-1 operability assessment committee, and contributed to the analysis and interpretation of data; E.M. was a member of the steering committee for CHEST-1 and contributed to the analysis and interpretation of data. All authors contributed to the writing and revision of the article for intellectual content, and they have reviewed and approved the final version for submission.

Received for publication Dec 8, 2015; revisions received Feb 8, 2016; accepted for publication Feb 21, 2016; available ahead of print April 12, 2016.

Address for reprints: David P. Jenkins, BSc, MBBS, FRCS (CTh), MS, National Pulmonary Endarterectomy Service, Department of Cardiothoracic Surgery, Papworth Hospital, Cambridge, CB23 3RE, United Kingdom (E-mail: david. jenkins@papworth.nhs.uk).

$0022-5223 / \$ 36.00$

Copyright (C) 2016 by The American Association for Thoracic Surgery

http://dx.doi.org/10.1016/j.jtcvs.2016.02.062 


\section{Abbreviations and Acronyms \\ CHEST-1 = Chronic Thromboembolic Pulmonary Hypertension Soluble Guanylate Cyclase-Stimulator Trial-1 \\ $\mathrm{CT}=$ computed tomography \\ $\mathrm{CTEPH}=$ chronic thromboembolic pulmonary hypertension \\ PVR = pulmonary vascular resistance}

Chronic thromboembolic pulmonary hypertension (CTEPH) is characterized by obstruction of the pulmonary vasculature by residual organized thrombi, ${ }^{1,2}$ leading to increased pulmonary vascular resistance (PVR), progressive pulmonary hypertension, and right ventricular failure. ${ }^{3-5}$ CTEPH is a major cause of severe pulmonary hypertension, yet the disease remains underdiagnosed. ${ }^{6}$ Early diagnosis is essential to identify the most appropriate treatment, without which prognosis is poor. ${ }^{6,7}$

Pulmonary endarterectomy is the recommended treatment for CTEPH and is potentially curative. ${ }^{8,9}$ However, patients who have distal disease may not benefit from pulmonary endarterectomy, and patients who have certain comorbidities are ineligible, whereas others have persistent/recurrent pulmonary hypertension after surgery. ${ }^{6,8-10}$ For some of these patients, specifically those deemed technically inoperable owing to distal disease, and those who have persistent/recurrent pulmonary hypertension after pulmonary endarterectomy, medical therapy should be considered.

Appropriate assessment of operability is vital to ensure that patients receive the most suitable treatment, and that patients who have operable disease are not misclassified and denied pulmonary endarterectomy. However, the assessment of operability is subjective and challenging ${ }^{8}$; in the absence of a risk-stratification scoring system, making a consistent assessment is difficult, in both clinical practice and multicenter clinical trials in CTEPH. In view of this, all patients who have suspected CTEPH should be referred to an expert center for confirmation of diagnosis, assessment of operability, and treatment. ${ }^{8,11,12}$

Nonetheless, in patients with truly inoperable disease and those who have symptomatic residual/recurrent pulmonary hypertension after pulmonary endarterectomy, specific drug therapy for pulmonary hypertension may play a role. Previous randomized controlled studies of pulmonary arterial hypertension-targeted medications in patients who have CTEPH have shown variable clinical effectiveness. ${ }^{13,14}$ Riociguat, a novel soluble guanylate cyclase stimulator ${ }^{15-17}$ is approved for the treatment of inoperable or persistent/recurrent CTEPH, based on the pivotal phase III Chronic Thromboembolic Pulmonary Hypertension Soluble Guanylate Cyclase-Stimulator Trial-1 (CHEST-1) study. ${ }^{18}$

CHEST-1 was a multicenter, randomized, double-blind, placebo-controlled study; the primary endpoint was a change from baseline in 6-minute walking distance after 16 weeks of treatment. Rigorous adjudication in CHEST-1 guaranteed that only technically inoperable patients, and patients who had persistent/recurrent pulmonary hypertension, were enrolled. CHEST-1 was the first large randomized clinical trial of a pharmacotherapy in CTEPH to demonstrate statistically significant effectiveness, in terms of both increased 6-minute walking distance $(+39 \mathrm{~m})$ and reduced PVR $\left(-226 \mathrm{dyn} / \mathrm{s} / \mathrm{cm}^{-5}\right)$ in patients who had inoperable CTEPH or persistent/recurrent pulmonary hypertension after pulmonary endarterectomy. ${ }^{18}$ Here, we report the impact of the unique methodology employed to assess operability in CHEST-1 and discuss its implications for future clinical trials and clinical practice.

\section{CURRENT GUIDELINE RECOMMENDATIONS}

Current CTEPH guidelines recommend that diagnosis of CTEPH be carried out in a stepwise process, starting with echocardiography to assess the right ventricle and ventilation/perfusion scintigraphy (Figure E1) to look for mismatched perfusion defects (with a normal ventilation/ perfusion scan, excluding CTEPH as a diagnosis). Once CTEPH is diagnosed, operability assessment requires at least one more good-quality radiologic investigation to examine the anatomic pattern of the occlusive thromboembolic disease, preferably a catheter-based selective pulmonary angiography in 2 planes. $^{8}$ High-quality computed tomography or magnetic resonance angiography are potentially suitable investigations in experienced CTEPH centers. Recurrent disease is relatively rare if anticoagulation is well controlled. However, if patients experience recurrent breathlessness, the investigations need to be repeated. ${ }^{8}$

Despite sophisticated imaging techniques, the assessment of technical feasibility of pulmonary endarterectomy, as dictated by the angiographic pattern of obstruction, is subjective and depends on the experience of the surgeon. ${ }^{8}$ Furthermore, the correlation between the extent of thromboembolic obstruction and the degree of pulmonary hypertension influences any risk-benefit analysis. Radiographic and hemodynamic evaluations must be performed in tandem to determine operability and estimate the relative risk from undergoing pulmonary 
endarterectomy surgery. ${ }^{6,19}$ Consequently, an expert team consisting of an experienced pulmonary endarterectomy surgeon, a radiologist, and CTEPH physicians always should assess operability before alternative treatments are considered. ${ }^{8}$ Moreover, re-evaluation of operability by a second experienced center is recommended if a patient is considered inoperable. ${ }^{8,12}$

Factors that are associated with a good result from pulmonary endarterectomy include a positive history of pulmonary embolism, bilateral lower-lobe web occlusions (best seen in a lateral pulmonary angiogram), and at least 8 occluded segments. Although no limit on PVR prohibits undertaking the procedure, the risk of surgery is generally lower when the PVR is $<1000 \mathrm{dyn} / \mathrm{s} / \mathrm{cm}^{-5}$ and increases when the PVR is $>1200 \mathrm{dyn} / \mathrm{s} / \mathrm{cm}^{-5}$.

\section{OPERABILITY ASSESSMENT IN PREVIOUS CTEPH TRIALS}

Operability assessment methods have varied in the few randomized controlled trials of pharmacologic therapies in patients who have inoperable CTEPH. In a pilot study $(\mathrm{n}=19)$ investigating sildenafil for treating distal CTEPH or persistent pulmonary hypertension $>3$ months after pulmonary endarterectomy, ${ }^{14} \mathrm{CTEPH}$ diagnosis was confirmed by appropriate imaging. In that study, imaging was reviewed by a panel of specialist physicians, radiologists, and surgeons, to determine the distribution of disease.

Before CHEST-1, the largest multicenter, randomized, placebo-controlled study $(\mathrm{n}=157)$ that had been undertaken was the Bosentan Effects in Inoperable Forms of Chronic Thromboembolic Pulmonary Hypertension (BENEFiT) trial, which investigated the effect of bosentan on PVR and/or exercise capacity in patients who have inoperable or persistent/recurrent CTEPH. ${ }^{13}$ In BENEFiT, the operability of each patient was evaluated by a qualified surgeon or an experienced physician before enrollment; the inoperability of randomized patients was verified retrospectively before unblinding by an operability evaluation committee, consisting of 2 specialized pulmonologists and 2 pulmonary endarterectomy surgeons.

\section{CHEST-1 OPERABILITY ASSESSMENT PROCEDURE}

The phase III randomized, placebo-controlled CHEST-1 study (NCT00855465) evaluated riociguat for the treatment of inoperable CTEPH or persistent/recurrent pulmonary hypertension after pulmonary endarterectomy. The full methodology and results of the study are described elsewhere. ${ }^{18}$ The institutional review board at each participating center approved the study protocol, and data were collected according to good clinical practice guidelines at the investigation sites. Written informed consent was obtained from all patients.
The CHEST-1 study was designed in accordance with guidelines for the diagnosis of CTEPH and assessment of operability. ${ }^{8}$ As such, all screened patients initially considered "inoperable" by the study investigators underwent independent confirmatory adjudication for technical inoperability during the pretreatment phase of CHEST-1, before randomization. This assessment was undertaken by an adjudication committee (nominated by the sponsor) composed of 6 experienced pulmonary endarterectomy surgeons from the world's leading expert CTEPH centers (Table E1). Members of the committee were available for remote consultation by computer at all times, and they received all relevant documents, data, and medical images from the study investigator.

When an experienced surgeon collaborated with the study center regarding a patient's regular diagnostic workup, local confirmatory adjudication of the patient's inoperability was permitted instead of central adjudication. Surgeons were regarded as experienced if they had performed $>20$ pulmonary endarterectomies in the year they started to assess study cases, and/or $>20$ in the year before they started to assess study cases, and/or $>40$ in the 3 years before they started to assess study cases.

Operability was assessed based on the following criteria: (1) surgical accessibility of the organized thrombi; and (2) concordance between surgically accessible vascular obstruction and PVR. Reasons for inoperability were recorded on a standardized form (Figure E2) and included: predominantly distal disease; an expectation that pulmonary endarterectomy would not reduce PVR by $>50 \%$; or other reasons. This decision was based on, at a minimum, pulmonary angiography supplemented by ventilation/perfusion scintigraphy, or CT pulmonary angiography (minimum 64-slice spiral CT with contrast medium) supplemented by ventilation/perfusion scintigraphy. In addition to well-defined high-quality imaging, investigators were required to provide adjudicators with the patient's medical history and most-recent hemodynamic data (at least mean right atrial pressure, mean pulmonary arterial pressure, PVR, cardiac output, and pulmonary arterial wedge pressure). The same operability assessment criteria were applied, regardless of whether the patient was adjudicated centrally or locally. Investigators were informed when the adjudicators considered a patient to be operable.

\section{IMAGING IN CHEST-1}

Most patients initially considered to be inoperable by the investigators were referred for adjudication with pulmonary angiography, CT angiography, and ventilation/ perfusion scintigraphy results (35\%), or CT angiography and ventilation/perfusion scintigraphy results (34\%) (Figure 1). Pulmonary angiography, the recommended 


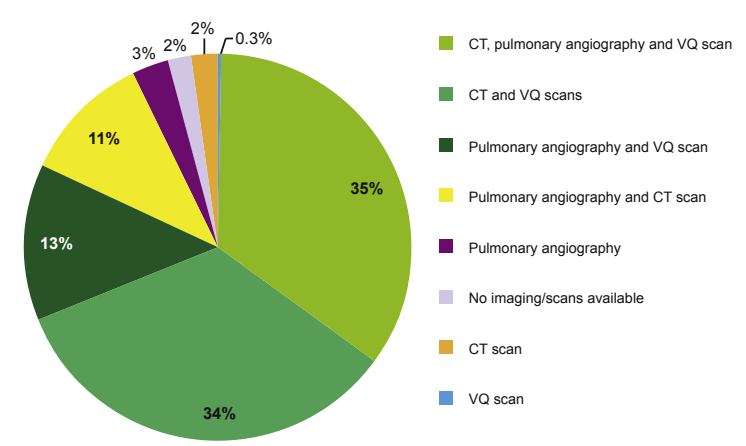

FIGURE 1. Images and examinations used by the investigators to diagnose patients as "inoperable" prior to referral for central or local adjudication. $C T$, Computed tomography; $V Q$, ventilation/perfusion.

technique for evaluating operability, had been undertaken in $62 \%$ of patients who were referred; ventilation/perfusion scintigraphy, the recommended screening test for CTEPH, was carried out in $82 \%$ of patients; and imaging was not available for $2 \%$ of patients.

\section{SCREENING AND ADJUDICATION OF OPERABILITY FOR PATIENTS IN CHEST-1}

Basic demographic information collected from screened patients who underwent adjudication (Table 1) shows that patients adjudicated locally were slightly older than patients who were adjudicated centrally (mean age: 62 vs 58 years), and $69 \%$ of all inoperable patients were women. The geographic distribution of patients is shown in Table 2.

A total of 446 patients were initially screened for CHEST-1 (Figure 2), and 134 (30\%) had persistent/ recurrent pulmonary hypertension after pulmonary endarterectomy, of whom $72(54 \%)$ were eligible, randomized, and treated. The remaining 312 patients were initially considered by the study investigators to be "inoperable" and were sent for adjudication centrally
$(60 \%)$ or locally $(40 \%)$. After adjudication, $69(22 \%)$ of these "inoperable" cases were deemed to be operable; assessment was not possible in 17 cases $(5 \%)$ (mainly because of poor-quality imaging). Of the 226 patients $(72 \%)$ who maintained their classification as inoperable, 189 met the study eligibility criteria and were randomized and treated.

\section{LESSONS FROM CHEST-1 AND IMPLICATIONS FOR FUTURE PRACTICE}

In CHEST-1, all patients initially considered to be "inoperable" by study investigators were referred for central or local adjudication, to ensure that only technically inoperable patients were classified as such and enrolled. Misclassifying patients as being inoperable has considerable consequences, including denying these patients the possibility of receiving potentially curative surgery. Inclusion of inoperable patients assessed by a local experienced surgeon was permitted only after an amendment was made to the CHEST-1 study protocol, owing to low recruitment into the study. Nevertheless, an exploratory post hoc subgroup analysis found that the improvements in mean \pm SD 6MWD observed with riociguat at week 16 were similar in patients adjudicated centrally (riociguat: $+39 \pm 83 \mathrm{~m}$; placebo: $-10 \pm 72 \mathrm{~m}$ ) and locally (riociguat: $+49 \pm 84 \mathrm{~m}$; placebo: $-5 \pm 105 \mathrm{~m}$ ), suggesting that the adjudication methods concurred.

Where there was no local expert CTEPH center, central adjudication demonstrated the utility of a remote expert opinion. Current guidelines recommend that participation in clinical trials be restricted to patients who have been diagnosed as inoperable by experienced CTEPH teams situated at referral centers. ${ }^{6,11}$ Thus, the remote central adjudication of patients in CHEST-1 allowed patients from nonreferral centers to be included. This approach could be used to extend clinical trial participation to such patients in future studies.

TABLE 1. Baseline demographics of screened patients who underwent adjudication in the CHEST-1 study

\begin{tabular}{|c|c|c|c|c|c|c|c|c|c|c|c|c|}
\hline \multirow[b]{2}{*}{ Parameter } & \multicolumn{4}{|c|}{ Total } & \multicolumn{4}{|c|}{ Central adjudication } & \multicolumn{4}{|c|}{ Local adjudication } \\
\hline & $\begin{array}{c}\text { Operable } \\
(\mathbf{n}=69)\end{array}$ & $\begin{array}{c}\text { Inoperable } \\
(\mathbf{n}=\mathbf{2 2 6})\end{array}$ & $\begin{array}{c}\text { Assessment } \\
\text { not possible } \\
(\mathrm{n}=17)\end{array}$ & $\begin{array}{c}\text { Total } \\
(\mathbf{n}=\mathbf{3 1 2})\end{array}$ & $\begin{array}{c}\text { Operable } \\
(n=48)\end{array}$ & $\begin{array}{c}\text { Inoperable } \\
(\mathbf{n}=125)\end{array}$ & $\begin{array}{c}\text { Assessment } \\
\text { not possible } \\
(\mathbf{n}=15)\end{array}$ & $\begin{array}{c}\text { Total } \\
(\mathbf{n}=\mathbf{1 8 8})\end{array}$ & $\begin{array}{c}\text { Operable } \\
(\mathbf{n}=\mathbf{2 1})\end{array}$ & $\begin{array}{c}\text { Inoperable } \\
(\mathbf{n}=101)\end{array}$ & $\begin{array}{c}\text { Assessment } \\
\text { not possible } \\
(\mathbf{n}=2)\end{array}$ & $\begin{array}{c}\text { Total } \\
(\mathrm{n}=\mathbf{1 2 4})\end{array}$ \\
\hline Female & $38(55)$ & $156(69)$ & $11(65)$ & $205(66)$ & $26(54)$ & $91(73)$ & $9(60)$ & $126(67)$ & $12(57)$ & $65(64)$ & $2(100)$ & $79(64)$ \\
\hline \multicolumn{13}{|l|}{ Race } \\
\hline White & $42(61)$ & $148(65)$ & $8(47)$ & $198(63)$ & $24(50)$ & $81(65)$ & $6(40)$ & $111(59)$ & $18(86)$ & $67(66)$ & $2(100)$ & $87(70)$ \\
\hline Black & 0 & $8(4)$ & 0 & $8(3)$ & 0 & $7(6)$ & 0 & $7(4)$ & 0 & $1(1)$ & 0 & $1(1)$ \\
\hline Asian & $20(29)$ & $57(25)$ & $7(41)$ & $84(27)$ & $17(35)$ & $24(19)$ & $7(47)$ & $48(26)$ & $3(14)$ & $33(33)$ & 0 & $36(29)$ \\
\hline Other/not reported & $7(10)$ & $13(6)$ & $2(12)$ & $22(7)$ & $7(15)$ & $13(10)$ & $2(13)$ & $22(12)$ & 0 & 0 & 0 & 0 \\
\hline Mean age y (SD) & $59(13)$ & $60(13)$ & $59(10)$ & $60(13)$ & $57(13)$ & $59(14)$ & $58(11)$ & $58(13)$ & $64(11)$ & $61(13)$ & $61(11)$ & $62(12)$ \\
\hline
\end{tabular}

Values are $\mathrm{n}(\%)$, unless otherwise indicated. $S D$, Standard deviation. 
TABLE 2. Geographic distribution of central and local adjudication, and details of the proportions of patients classified as operable, inoperable, or in whom assessment was not possible, in each region

\begin{tabular}{|c|c|c|c|c|c|c|c|c|}
\hline \multirow[b]{2}{*}{ Region } & \multicolumn{4}{|c|}{ Central adjudication $(n=188)$} & \multicolumn{4}{|c|}{ Local adjudication $(n=124)$} \\
\hline & $\begin{array}{c}\text { Operable } \\
(n=48)\end{array}$ & $\begin{array}{c}\text { Inoperable } \\
(n=125)\end{array}$ & $\begin{array}{c}\text { Assessment } \\
\text { not possible } \\
(\mathrm{n}=15) \\
\end{array}$ & $\begin{array}{c}\text { Total } \\
(\mathbf{n}=\mathbf{1 8 8})\end{array}$ & $\begin{array}{c}\text { Operable } \\
(\mathrm{n}=\mathbf{2 1})\end{array}$ & $\begin{array}{c}\text { Inoperable } \\
(\mathrm{n}=101)\end{array}$ & $\begin{array}{c}\text { Assessment } \\
\text { not possible } \\
(\mathbf{n}=\mathbf{2}) \\
\end{array}$ & $\begin{array}{c}\text { Total } \\
(\mathrm{n}=124\end{array}$ \\
\hline Asia/Pacific & $6(13)$ & $13(10)$ & $1(7)$ & $20(11)$ & $1(5)$ & $15(15)$ & 0 & $16(13)$ \\
\hline China & $12(25)$ & $13(10)$ & $6(40)$ & $31(16)$ & $2(10)$ & $18(18)$ & 0 & $20(16)$ \\
\hline Europe & $21(44)$ & $58(46)$ & $5(33)$ & $84(45)$ & $18(86)$ & $65(64)$ & $2(100)$ & $85(69)$ \\
\hline North America & $2(4)$ & $21(17)$ & 0 & $23(12)$ & 0 & $3(3)$ & 0 & $3(2)$ \\
\hline Latin America & $7(15)$ & $20(16)$ & $3(20)$ & $30(16)$ & 0 & 0 & 0 & 0 \\
\hline
\end{tabular}

This study provided evidence that operability guidelines, to which CHEST-1 strictly adhered, are not being followed rigorously in clinical practice. Further work is required to promote the appropriate diagnosis and assessment of operability in CTEPH in clinical practice, and improve access to a second opinion such that patients with operable CTEPH are identified robustly. One such endeavor is an online platform for pulmonary endarterectomy surgeons, CTEPH specialists, and radiologists to share cases (www.ctephassociation.org/educational-platform), which has been developed recently by the International CTEPH Association. This approach allows second opinions to be garnered from additional expert sites, while providing support and training to emerging sites and promoting intersite networking. The advent of such remote central adjudication platforms raises the possibility that similar approaches could be implemented to make the process more feasible in "real life."

The method described here may serve as a model for future clinical studies, as well as for operability assessment in clinical practice. Several ongoing/recently completed clinical studies in patients who have CTEPH have included prospective operability assessment in their trial designs. The phase II MERIT- 1 trial will assess ${ }^{20}$ macitentan in patients who have inoperable CTEPH, as judged by a remote central adjudication committee to have localization of the obstruction that is surgically inaccessible, with study completion anticipated to be in 2016 .

\section{CONCLUSIONS}

Operability assessment in CTEPH is a complex and subjective process. ${ }^{8}$ Therefore, all patients who have suspected CTEPH should undergo operability assessment by an expert pulmonary endarterectomy team. Building on retrospective operability assessment procedures used in previous trials, CHEST-1 included a rigorous prospective assessment of operability by expert pulmonary endarterectomy surgeons that guaranteed that only technically inoperable patients, or patients with persistent/recurrent pulmonary hypertension after pulmonary endarterectomy,

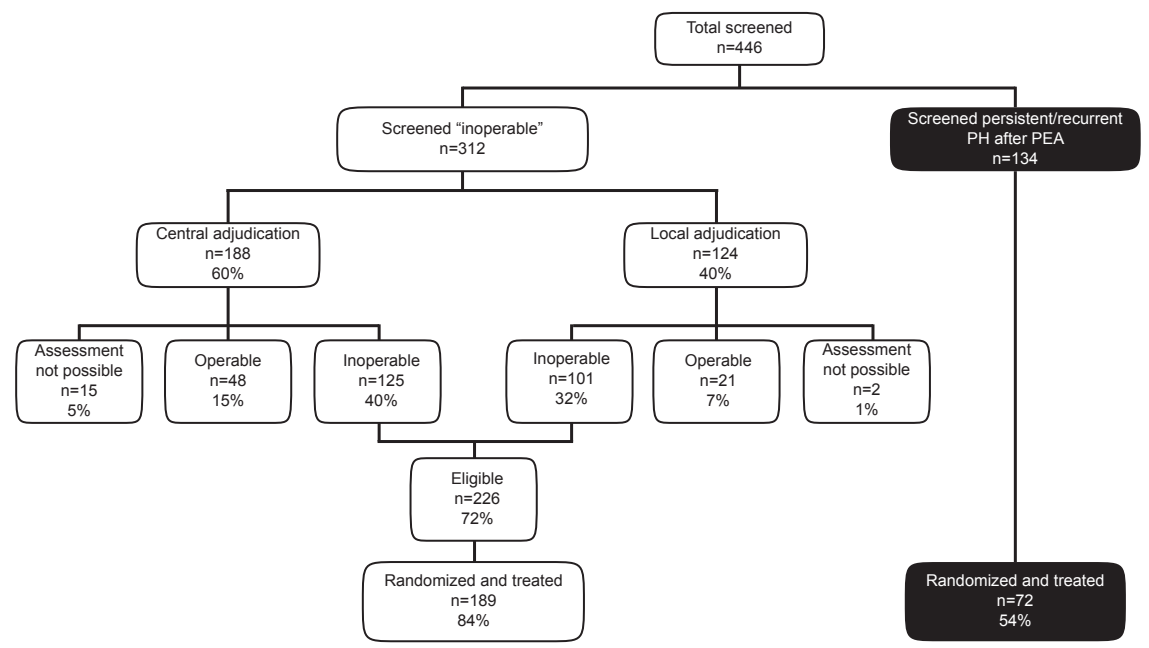

FIGURE 2. Patient disposition: patients considered inoperable, operable, or in whom operability assessment was not possible; and randomized and treated patients in the CHEST-1 study. $P H$, Pulmonary hypertension; $P E A$, pulmonary endarterectomy. 
were enrolled. This approach ensured that patients received the treatment modality that would benefit their condition most. The study design of CHEST-1 sets new standards for future clinical trials of medical therapies and clinical practice.

\section{Conflict of Interest Statement}

D.P.J. reports receiving personal fees from Bayer HealthCare, GSK, Actelion, and Pfizer. A.M.D. reports receiving personal fees from Bayer HealthCare and Actelion. M.M.M. reports receiving personal fees from Bayer HealthCare. E.M. reports receiving personal fees and nonfinancial support from Bayer HealthCare, and personal fees from Actelion, GlaxoSmithKline, and Pfizer. All other authors have nothing to disclose with regard to commercial support.

The CHEST-1 study was supported by Bayer Pharma AG (Berlin, Germany). Editorial assistance was provided by Adelphi Communications Ltd (Bollington, United Kingdom), sponsored by Bayer Pharma AG.

\section{References}

1. Moser KM, Bloor CM. Pulmonary vascular lesions occurring in patients with chronic major vessel thromboembolic pulmonary hypertension. Chest. 1993; 103:685-92.

2. Simonneau G, Robbins IM, Beghetti M, Channick RN, Delcroix M, Denton CP, et al. Updated clinical classification of pulmonary hypertension. J Am Coll Cardiol. 2009;54(Suppl):S43-54.

3. Humbert M. Pulmonary arterial hypertension and chronic thromboembolic pulmonary hypertension: pathophysiology. Eur Respir Rev. 2010;19:59-63.

4. Lang IM, Klepetko W. Chronic thromboembolic pulmonary hypertension: an updated review. Curr Opin Cardiol. 2008;23:555-9.

5. Peacock A, Simonneau G, Rubin L. Controversies, uncertainties and future research on the treatment of chronic thromboembolic pulmonary hypertension. Proc Am Thorac Soc. 2006;3:608-14.

6. Jenkins D, Mayer E, Screaton N, Madani M. State-of-the-art chronic thromboembolic pulmonary hypertension diagnosis and management. Eur Respir Rev. 2012;21:32-9.

7. Dalen JE, Alpert JS. Natural history of pulmonary embolism. Prog Cardiovasc Dis. 1975;17:259-70.
8. Kim NH, Delcroix M, Jenkins DP, Channick R, Dartevelle P, Jansa P, et al. Chronic thromboembolic pulmonary hypertension. J Am Coll Cardiol. 2013;62 (Suppl):D92-9.

9. Mayer E, Jenkins D, Lindner J, D’Armini A, Kloek J, Meyns B, et al. Surgical management and outcome of patients with chronic thromboembolic pulmonary hypertension: results from an international prospective registry. J Thorac Cardiovasc Surg. 2011;141:702-10.

10. Pepke-Zaba J, Delcroix M, Lang I, Mayer E, Jansa P, Ambroz D, et al. Chronic thromboembolic pulmonary hypertension $(\mathrm{CTEPH})$ : results from an international prospective registry. Circulation. 2011;124:1973-81.

11. Galiè N, Humbert M, Vachiery JL, Gibbs S, Lang I, Torbicki A, et al. 2015 ESC/ERS Guidelines for the diagnosis and treatment of pulmonary hypertension: The Joint Task Force for the Diagnosis and Treatment of Pulmonary Hypertension of the European Society of Cardiology (ESC) and the European Respiratory Society (ERS): Endorsed by: Association for European Paediatric and Congenital Cardiology (AEPC), International Society for Heart and Lung Transplantation (ISHLT). Eur Respir J. 2015;46:903-75.

12. Wilkens H, Lang I, Behr J, Berghaus T, Grohe C, Guth S, et al. Chronic thromboembolic pulmonary hypertension (CTEPH): updated recommendations of the Cologne Consensus Conference 2011. Int J Cardiol. 2011;154 (Suppl 1):S54-60.

13. Jais X, D’Armini AM, Jansa P, Torbicki A, Delcroix M, Ghofrani HA, et al. Bosentan for treatment of inoperable chronic thromboembolic pulmonary hypertension: BENEFiT (Bosentan Effects in iNopErable Forms of chronIc Thromboembolic pulmonary hypertension), a randomized, placebo-controlled trial. J Am Coll Cardiol. 2008;52:2127-34.

14. Suntharalingam J, Treacy CM, Doughty NJ, Goldsmith K, Soon E, Toshner MR, et al. Long-term use of sildenafil in inoperable chronic thromboembolic pulmonary hypertension. Chest. 2008;134:229-36.

15. Stasch JP, Hobbs AJ. NO-independent, haem-dependent soluble guanylate cyclase stimulators. Handbook Exper Pharmacol. 2009;191:277-308.

16. Stasch JP, Pacher P, Evgenov OV. Soluble guanylate cyclase as an emerging therapeutic target in cardiopulmonary disease. Circulation. 2011;123: 2263-73.

17. Stasch JP, Evgenov OV. Soluble guanylate cyclase stimulators in pulmonary hypertension. Handbook Exper Pharmacol. 2013;218:279-313.

18. Ghofrani HA, D'Armini AM, Grimminger F, Hoeper MM, Jansa P, Kim NH, et al. Riociguat for the treatment of chronic thromboembolic pulmonary hypertension. N Engl J Med. 2013;369:319-29.

19. Auger WR, Kim NH, Trow TK. Chronic thromboembolic pulmonary hypertension. Clin Chest Med. 2010;31:741-58.

20. MERIT-1: Macitentan in the treatment of inoperable chronic thromboembolic pulmonary hypertension: NCT02021292. Available at: https://clinicaltrials. gov/ct2/show/NCT02021292. Accessed October 7, 2015.

Key Words: chronic thromboembolic pulmonary hypertension, pulmonary endarterectomy, operability assessment 


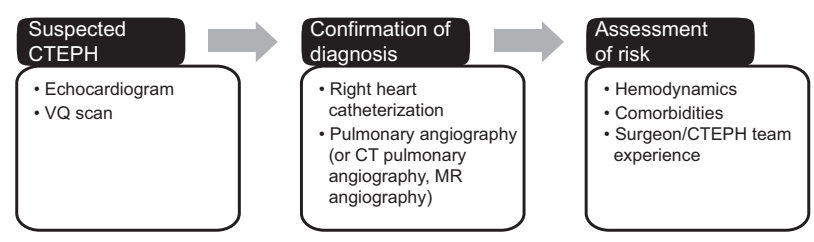

FIGURE E1. Current recommendation for diagnosis and operability assessment in CTEPH. Figure based on Jenkins and colleagues. ${ }^{6}$ CTEPH, Chronic thromboembolic pulmonary hypertension; $V Q$, ventilation/ perfusion; $C T$, computed tomography; $M R$, magnetic resonance. 


\section{A}

\begin{tabular}{|c|c|c|c|c|c|}
\hline \multicolumn{3}{|c|}{ Subject identification and demography } & \multicolumn{3}{|c|}{ Does the patient have a history of inflammatory bowel disease? } \\
\hline \multicolumn{3}{|c|}{\begin{tabular}{|l|l|} 
Patient number &
\end{tabular}} & If yes, specify & \multirow[t]{2}{*}{ Start date } & Stop date \\
\hline Gender & & & 1. & & \\
\hline Age at study inclusion & & & $\downarrow$ & $\downarrow$ & $\downarrow$ \\
\hline Height & & & \multicolumn{3}{|c|}{ Does the patient have a history of myeloproliferative disease? } \\
\hline \multicolumn{2}{|l|}{$\begin{array}{l}\text { Weight } \\
\text { Medical history }\end{array}$} & & If yes, specify & Start date & Stop date \\
\hline \multicolumn{3}{|l|}{ Medical history } & \multicolumn{3}{|l|}{1.} \\
\hline \multicolumn{3}{|c|}{ When was the initial diagnosis of CTEPH made? } & $\downarrow$ & $\downarrow$ & $\downarrow$ \\
\hline \multicolumn{3}{|c|}{ Date } & \multicolumn{3}{|c|}{ Other clinically relevant diseases or symptoms: } \\
\hline & Disease/Symptom & Start date & Stop date \\
\hline \multicolumn{3}{|c|}{$\begin{array}{l}\text { Does the patient have a history of deep vein thrombosis? } \\
\text { Yes/No }\end{array}$} & 1. & & \\
\hline If yes, localization & \multicolumn{2}{|l|}{ Date } & $\downarrow$ & $\downarrow$ & $\downarrow$ \\
\hline \multicolumn{3}{|l|}{1.} & \multirow{2}{*}{\multicolumn{3}{|c|}{$\begin{array}{l}\text { Description of clinical signs and symptoms, including results of } \\
\text { clinical relevant investigations (e.g. Ventilation - Perfusion Scan): }\end{array}$}} \\
\hline$\downarrow$ & \multicolumn{2}{|l|}{$\downarrow$} & & & \\
\hline \multicolumn{3}{|c|}{ Does the patient have a history of pulmonary embolism? } & & & \\
\hline \multicolumn{3}{|c|}{\begin{tabular}{|l|l} 
Yes/No & \\
\end{tabular}} & & & \\
\hline If yes, localization & \multicolumn{2}{|l|}{ Date } & & & \\
\hline \multicolumn{3}{|l|}{1.} & & & \\
\hline$\downarrow$ & \multicolumn{2}{|c|}{$\downarrow$} & & & \\
\hline \multicolumn{3}{|c|}{ Does the patient have a history of splenectomy? } & & & \\
\hline \multirow[t]{2}{*}{ If yes, specify } & Date & & Right heart catheterization/He & odynamic m & rements \\
\hline & & & Date of investigation & & \\
\hline Does the patient have & f ventriculo & I shunt? & Mean right atrial pressure & & \\
\hline If yes, specify & Start date & Stop date & $(\mathrm{mmHg})$ & & \\
\hline 1. & & & Systolic pulmonary arterial & & \\
\hline$\downarrow$ & $\downarrow$ & $\downarrow$ & pressure $(\mathrm{mmHg})$ & & \\
\hline Does the patient have & f osteomye & & Mean pulmonary arterial & & \\
\hline If yes, specify & Start date & Stop date & pressure $(\mathrm{mmHg})$ & & \\
\hline 1. & & & Diastolic pulmonary arterial & & \\
\hline$\downarrow$ & $\downarrow$ & $\downarrow$ & pressure $(\mathrm{mmHg})$ & & \\
\hline & & & $\begin{array}{l}\text { Pulmonary capillary wedge } \\
\text { pressure }(\mathrm{mmHg})\end{array}$ & & \\
\hline & & & Cardiac output (L/min) & & \\
\hline & & & Cardiac index $\left(\mathrm{L} / \mathrm{min} / \mathrm{m}^{2}\right)$ & & \\
\hline & & & $\begin{array}{l}\text { Pulmonary vascular resistance } \\
\text { (dyn } \mathrm{s} \cdot \mathrm{cm}^{-5} \text { ) }\end{array}$ & & \\
\hline & & & $\begin{array}{l}\text { Pulmonary vascular resistance } \\
\text { index }\left(\text { dyn } \cdot \mathrm{s} \cdot \mathrm{cm}^{-5}\right)\end{array}$ & & \\
\hline & & & $\begin{array}{l}\text { Systemic vascular resistance } \\
\left(\text { dyn } \mathrm{s} \cdot \mathrm{cm}^{-5}\right)\end{array}$ & & \\
\hline & & & $\begin{array}{l}\text { Systemic vascular resistance } \\
\text { index }\left(\text { dyn } \cdot s \cdot \mathrm{cm}^{-5}\right)\end{array}$ & & \\
\hline & & & $\begin{array}{l}\text { Mixed venous oxygen- } \\
\text { saturation rate } \mathrm{SvO}_{2}(\%)\end{array}$ & & \\
\hline & & & WHO functional class & & \\
\hline & & & Class: & Date of ass & ent: \\
\hline & & & Date: & Signature: & \\
\hline
\end{tabular}

FIGURE E2. Template forms completed by adjudicators for (A) operability assessment information and (B) operability assessment report. CTEPH, Chronic thromboembolic pulmonary hypertension; WHO, World Health Organization; CHEST-1, Chronic Thromboembolic Pulmonary Hypertension Soluble Guanylate Cyclase-Stimulator Trial-1; MRI, magnetic resonance imaging; $C T$, computed tomography; $V Q$, ventilation/perfusion. 


\section{B}

\begin{tabular}{|l|l|}
\hline $\begin{array}{l}\text { Study BAY 63-2521/11348-CHEST-1 } \\
\text { Pretreatment visit -4 weeks }\end{array}$ & $\begin{array}{l}\text { Subject number: } \\
\text { Date completed: }\end{array}$ \\
\hline $\begin{array}{l}\text { Information provided to the investigator } \\
\text { Reader's assessment }\end{array}$ \\
\hline $\begin{array}{l}\text { Patient is technically operable with } \\
\text { respect to pulmonary endarterectomy in } \\
\text { CTEPH and therefore NOT ELIGIBLE for } \\
\text { the study }\end{array}$ & \\
\hline $\begin{array}{l}\text { Patient is NOT ELIGIBLE for the study } \\
\text { because the provided documents/ } \\
\text { images do not allow a proper operability } \\
\text { assessment with respect to pulmonary } \\
\text { endarterectomy in CTEPH }\end{array}$ & \\
\hline $\begin{array}{l}\text { Patient is considered as inoperable with } \\
\text { respect to pulmonary endarterectomy in } \\
\text { CTEPH and CAN BE RANDOMIZED }\end{array}$ & \multicolumn{1}{|l|}{} \\
\hline \begin{tabular}{l} 
Reader's comments with respect to the operability assessment: \\
\hline $\begin{array}{l}\text { The following imaging studies and documents were available for the } \\
\text { inoperability assessment: }\end{array}$
\end{tabular} & $\square$ Other/dated: \\
\hline$\square$ Pulmonary angiogram/dated: & $\square$ Operability assessment \\
\hline$\square$ CT pulmonary angiogram/dated: & \\
\hline$\square$ V/Q scan/dated: & \\
\hline Date & \\
\hline
\end{tabular}

FIGURE E2. (Continued).

TABLE E1. Operability assessment committee for central adjudication of patients with inoperable chronic thromboembolic pulmonary hypertension screened for the CHEST study

CHEST Operability Assessment Committee members

Professor Andrzej Biederman

Department of Cardiac Surgery,

Allenort Hospital,

Warsaw,

Poland.

Professor Andrea M. D’Armini

Division of Cardiothoracic Surgery,

Foundation "I.R.C.C.S. Policlinico San Matteo,"

University of Pavia School of Medicine,

Pavia,

Italy.

Mr David P. Jenkins

National Pulmonary Endarterectomy Service,

Department of Cardiothoracic Surgery,

Papworth Hospital,

Cambridge,

UK.
Professor Walter Klepetko

Department of Thoracic Surgery,

Vienna General Hospital,

Medical University of Vienna,

Vienna,

Austria.

Professor Jaroslav Lindner

Charles University Prague,

First Faculty of Medicine and General Teaching Hospital,

2nd Surgical Department-Clinical Department of Cardiovascular Surgery,

Prague,

Czech Republic.

Professor Michael M. Madani

Division of Cardiovascular and Thoracic Surgery,

University of California San Diego Medical Center,

San Diego, California. 